\title{
USING CHANGES IN EATING AND RUMINATION TIME TO INDICATE THE ONSET OF PARTURITION OR CHANGES IN THE HEALTH STATUS OF DAIRY COWS
}

\author{
Radim Codl ${ }^{1}$, Jaromír Ducháček ${ }^{1}$, Jan Pytlík ${ }^{1}$, Mojmír Vacek¹, Marek Vrhel $^{1}$ \\ ${ }^{1}$ Department of Animal Science, Faculty of Agrobiology, Food and Natural Resources, Czech University of Life \\ Sciences Prague, Kamýcká 129, 16500 Prague-Suchdol, Czech Republic
}

Link to this article: https://doi.org/10.11118/actaun.2021.049

Received: 14. 6. 2021, Accepted: 26. 8. 2021

To cite this article: CODL RADIM, DUCHÁČEK JAROMÍR, PYTLÍK JAN, VACEK MOJMÍR, VRHEL MAREK. 2021. Using Changes in Eating and Rumination Time to Indicate the Onset of Parturition or Changes in the Health Status of Dairy Cows. Acta Universitatis Agriculturae et Silviculturae Mendelianae Brunensis, 69(5): 555-561.

\begin{abstract}
Monitoring the time of rumination and eating of dairy cows, by new technologies, is increasingly used in commercial herds. Evaluation of parameters obtained from Vitalimeter 5P, was performed in 656 dairy cows Czech Fleckvieh and Holstein cattle, including their crossbreeds. The aim of the study was evaluation the relationship between the impending calving, the occurrence of the diseases with a change in rumination, and eating time. On the day of birth, the rumination time decreased by $122.9 \mathrm{~min}$. and eating by $11.35 \mathrm{~min}$. compared to the normal state before calving. The decrease in rumination and eating on the day of calving was significantly $(\mathrm{P}<0.05)$ different depending on the lactation order. The decrease in rumination time and eating is also significant $(\mathrm{P}<0.01)$ with the onset of the diseases. In metabolic disorders, the rumination time decreased on the day of detection by $128.95 \mathrm{~min}$./day compared to the $3^{\text {rd }}$ day before the problem was detected. Following this, the eating time decreased by $72.03 \mathrm{~min}$./day. For postpartum diseases, the rumination time changed in day of detection by - $88.75 \mathrm{~min}$./day and the eating time by $-68.67 \mathrm{~min}$. against the normal set 3 days before the disease is detected. The lowest decreases in terms of rumination and eating occurred in the case of mastitis, when the eating time decreased by $36.28 \mathrm{~min}$. and a rumination time by $43.01 \mathrm{~min}$. This balanced decrease in both parameters did not manifest itself in other diseases. Our results show Vitalimetr 5P as a good tool for the detection onset of calving and diseases.
\end{abstract}

Keywords: dairy cattle, rumination, eating, onset of partutition, health

\section{INTRODUCTION}

Enlarge dairy herds and a shortage of workers lead to the need for ever-greater use of automation while ensuring dairy farming. Also, related to reducing the number of attendant's pressure to reduce the cost of milk production (Awasthi et al., 2016). This has reduced human contact with animals and thus reduced the possibility of early detection of changes in health. Therefore, in automatic farms, automatic monitoring systems capable of detecting changes in the health status of dairy cows are needed (Helwatkar et al., 2014).

The profitability of dairy farming largely depends on good management of the periparturient period. Therefore, early and accurate detection of the onset of calving is also important. Calving detection is difficult in modern breeding conditions with numerous herds (Benaissa et al., 2020). Visual signs signaling the onset of calving are known, but these signs show variability and their monitoring requires the physical presence of a person. Therefore, there 
is room for automatic monitoring systems to record changes in eating behavior and the use of these changes to indicate the onset of calving (Schirmann et al., 2013; Pahl et al., 2014). Eating and rumination belong among the cattle's basic vital signs associated with receiving and digesting food. Observing the feeding behavior of dairy cattle provides useful information about the health of the animal and approaching calving. Good health and welfare is a prerequisite for their normal feeding behavior. Eating behavior is essential in compiling the clinical picture of a sick animal. Therefore, eating and rumination are commonly monitored in sick cows during and after treatment (Braun et al., 2014). Dairy cattle health problems cause production losses, increase care costs and worsen animal welfare (González et al., 2008). The profitability of the herd is negatively affected by reduced milk production, lower reproduction, and shorter production life of these dairy cows. Therefore, early identification of cow diseases is key to herd health and profitability (Huzzey et al., 2007). Modern automatic monitoring systems can contribute to the early detection of changes in health and help the farmer to manage the dairy herd. The aim of this work was to evaluate changes in the time of eating and rumination (measured by Vitalitmetr 5P) depending on the oncoming calving and the occurrence of dairy health problems.

\section{MATERIALS AND METHODS}

Data from the herd of dairy cows of various observed 656 cows of the Czech Fleckvieh and Holstein breed and their crossbreeds. Obtained data from cows were used to evaluate the influence of the onset of calving and the occurrence of the disease on the change in eating and rumination time. Monitoring was carried out on a farm in the Olomouc Region, which is at an altitude of $458 \mathrm{~m}$ above sea level. Observations of dairy cows took place from $1^{\text {st }}$ October 2017 to $30^{\text {th }}$ September 2018. The cows in the herd had an average milk production of $9112 \mathrm{~kg}$ of milk in 305 days, with a fat content of $4.18 \%$ and a protein content of $3.55 \%$ During lactation, the dairy cows were housed in a reconstructed freestall barn with straw bedding. The cows calved in group pens, where the cows were moved about 3 weeks before the expected date of calving. The calved cows were then transferred to a group of cows after calving, where they remained for 10 to 20 days. From there, they were transferred to the production group of high-yielding dairy cows. For the evaluation of the disease, we grouped the diseases into three groups based on their similarity due to the frequency of occurrences:

1. mastitis;

2. postpartum diseases (metritis, retained placenta);

3. metabolic disorder (ketosis, acidosis, milk fever, resp. parturient paresis).
Data on daily total eating and rumination time in seconds were obtained using Vitalimeters 5P (FARMTEC a.s., Czech Republic) for our evaluation, we convert seconds to minutes.

Obtained database of data from Vitalitmeters 5P and FARMSOFT. The Vitalimetr 5P neck responder (Farmtec a.s.) was used to identify eating and rumination time. Rumination and eating, are recognised by accelerometers, and records can be analysed using a detection algorithm. The FARMSOFT is a dairy management software that collects data from Vitalimeter 5P, milking parlour, medication, treatment and reproduction records. The effect of the onset of calving on the time of eating and rumination was evaluated based on the average time of both activities during 10 days before calving (group 1), the observed time on calving day (group 2), and the average time during 10 days after calving (group 3). Eating and rumination time was recorded for three days before detection of the disease (day - 3, - 2, - 1) and the day of detection of the disease (day 0). Data from the management program was analyzed in SAS 9.4 (SAS $\AA$ 9.4, 2013) using the GLM method (analysis of variance). The REG procedure, the STEPWISE method, was used to select a suitable model for evaluating the indicators. A detailed evaluation of the significance of the differences between the effect levels was performed using the Tukey-Kramer test.

The following model equations were used for evaluation: To estimate the effect of calving on the time of eating and rumination.

$Y_{i j k}=\mu+P L_{i}+O_{j}+R_{k}+b_{1}^{*}(\mathrm{PLEM})+b_{2}^{*}(D A T)+e_{i j k l}$,

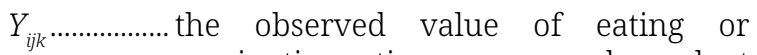
rumination time as a dependent variable (in minutes per day);

$\mu$.................... mean value of the dependent variable;

$P L_{i} \ldots \ldots \ldots \ldots . . . . . . .$. fixed effect of lactation order $(i=1$, $n=3050 ; i=2, n=4170 ; i=3, n=2847 ; i=4$, $n=1738 ; i=5$ and higher, $n=2065$ );

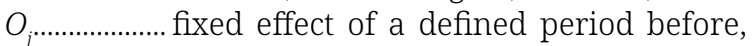
during and after calving ( $j=10$ days before calving, $n=876 ; j=$ calving day, $n=656$; $j=10$ days after calving, $n=12338$ );

$R_{k}$ …............ fixed effect of evaluated year $(k=2017$, $n=7290 ; k=2018, n=6580$ );

$b_{1}{ }^{*}(P L E M) .$. linear regression on belonging to the breed and hybrids;

$b_{2}{ }^{*}(D A T)$...... linear regresion on calving date;

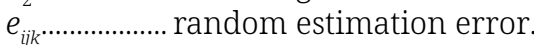

To estimate the effect of health disorders on the time of eating and rumination

$$
\begin{aligned}
Y_{i j k l m}= & \mu+P L_{i}+O_{j}+D_{k}+R_{l}+O D_{j k}+b_{1}^{*}(P L E M)+ \\
& +b_{2}{ }^{*}(D A T)+e_{i j k l m},
\end{aligned}
$$




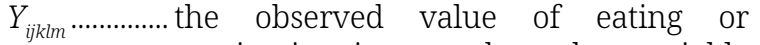
rumination time as a dependent variable (in minutes per day);

H.................. the mean value of the dependent variable;

$P L_{i}$................ fixed effect of lactation order $(i=1$, $n=371 ; i=2, n=575 ; i=3, n=482 ; i=4$, $n=330 ; i=5$ and higher, $n=405$ );

$O_{j}$.................. fixed effect of the type of disease ( $j$ = mastitis, $n=1829 ; j$ = postpartum diseases, $n=465 ; j=$ metabolic disorder, $n=65)$;

$D_{k}$................ fixed effect days before disease recording $(k=-3$ days, $n=391$; $k=-2$ days, $n=395 ; k=-1$ day, $n=397$; $k=$ day of recording, $n=1176)$;

$\mathrm{R}_{1}$................. fixed effect of evaluated year $(k=2017$, $n=7290 ; k=2018, n=6580$ );

$O D_{j k}$............. fixed effect of the interaction of the type of disease and the days before the recording of the disease ( $n=14$ to 881 );

$b_{1}^{*}$ (PLEM).. linear regression on belonging to the breed and hybrids;

$b_{2}{ }^{*}$ (DAT) ..... linear regresion on calving date;

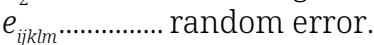

\section{RESULTS}

As part of the evaluation using the GLM procedure, the model equation for calving and for diseases evaluation were statistically significant $(\mathrm{P}<0.01)$ and explain from 13.13 to $38.75 \%$ of variability. It was confirmed that all effects included in the both model equation were statistically significant $(P<0,05)$ for the evaluation of the time of eating and rumination in the period around calving and health disorders.

The effect of the lactation order, year, and the period around calving on the time of eating and rumination in the peripartum period are shown in Tab. I. Statistically significant $(\mathrm{P}<0.05-0.01)$ highest values of eating time (230.19 min.) and rumination (388.44 min.) were observed in dairy cows on the second lactation. The average values of the eating time gradually decreased from the second to higher lactations. Between $1^{\text {st }}$ and $5^{\text {th }}$ and higher lactation was difference $47 \mathrm{~min}$. of eating time decrease. In the evaluation of the rumination time, lower differences were recorded between the average values of cows in each lactation (approx. 6-30 min.). However, even here there is a clear trend of a decrease in this time from the second to the next lactations. The significant effect of the year of follow-up was also confirmed ( $\mathrm{P}<0.01$ ). However, this difference was only about $9.5 \%$ for the eating time and $10.8 \%$ for the rumination time, but significant $(\mathrm{P}<0.05)$. Regarding the differences in the time of eating and rumination between the defined periods, the table shows a decrease in both variables on the day of calving $(-11.35 \mathrm{~min}$; or - $122.9 \mathrm{~min}$.). In the period after calving, there was an increase in the time of eating and rumination, when these values exceeded the original values from the period before calving. The differences between these periods were statistically significant $(\mathrm{P}<0.05-0.01)$. This decrease and subsequent increase were more pronounced at the time of rumination when there was an increase of $63.9 \%$ compared to the calving day.

Tab. II shows the evaluation of the time of eating and rumination as a function of the days before identification by, the order of lactation, the disease record and the type of disease. The evaluation of the effect of the days before recording the disease (treatment) shows that with the approaching disease there was a gradual decrease in both evaluated cases. Between the third and second day before the disease, there was a decrease of about

I: Influence of lactation order and the period around calving on time of eating and rumination in the perinatal period

\begin{tabular}{|c|c|c|c|}
\hline \multirow[b]{2}{*}{ Effect } & \multirow[b]{2}{*}{ Level } & Eating time & Rumination time \\
\hline & & $\begin{array}{c}\mathrm{LSM} \pm \text { SELSM } \\
\text { Min/day }\end{array}$ & $\begin{array}{c}\text { LSM } \pm \text { SELSM } \\
\text { Min/day }\end{array}$ \\
\hline \multirow{5}{*}{ Lactation order } & 1 & $212.12 \pm 2.519^{\mathrm{A}}$ & $367.08 \pm 3.430^{\mathrm{A}}$ \\
\hline & 2 & $230.19 \pm 2.279^{\mathrm{B}}$ & $388.44 \pm 3.103^{\mathrm{B}}$ \\
\hline & 3 & $203.04 \pm 2.389^{c}$ & $371.13 \pm 3.253^{\mathrm{A}, \mathrm{a}}$ \\
\hline & 4 & $186.40 \pm 2.629^{\mathrm{D}}$ & $358.72 \pm 3.580^{\mathrm{A}, \mathrm{b}}$ \\
\hline & 5 and higher & $165.09 \pm 2.526^{\mathrm{E}}$ & $364.65 \pm 3.440^{\mathrm{A}}$ \\
\hline \multirow{2}{*}{ Year of evaluation } & 2017 & $209.28 \pm 2.414^{\mathrm{A}}$ & $391.15 \pm 3.287^{\mathrm{A}}$ \\
\hline & 2018 & $189.46 \pm 2.343^{\mathrm{B}}$ & $348.86 \pm 3.190^{\mathrm{B}}$ \\
\hline \multirow{3}{*}{ Peripartal period } & 10 days before calving & $200.72 \pm 3.000^{\mathrm{a}}$ & $394.13 \pm 4.084^{\mathrm{A}}$ \\
\hline & Calving day & $189.37 \pm 3.334^{\mathrm{A}, \mathrm{b}}$ & $271.23 \pm 4.540^{\mathrm{B}}$ \\
\hline & 10 days after calving & $208.00 \pm 1.519^{\mathrm{B}, \mathrm{b}}$ & $444.66 \pm 2.068^{c}$ \\
\hline
\end{tabular}

Different letters in columns means statistical significance A,B,C,D $(\mathrm{P}<0.01)$; a,b $(\mathrm{P}<0.05)$. 
II: Influence of days before treatment, order of lactation, and disease groups on the time of eating and rumination

\begin{tabular}{|c|c|c|c|}
\hline \multirow[b]{2}{*}{ Efect } & \multirow[b]{2}{*}{ Level } & Eating time & Rumination time \\
\hline & & $\begin{array}{c}\mathrm{LSM} \pm \text { SELSM } \\
\text { Min/day }\end{array}$ & $\begin{array}{c}\mathrm{LSM} \pm \text { SELSM } \\
\text { Min/day }\end{array}$ \\
\hline \multirow{5}{*}{ Lactation order } & 1 & $196.11 \pm 6.967^{\mathrm{A}}$ & $363.61 \pm 9.835^{\mathrm{A}, \mathrm{a}}$ \\
\hline & 2 & $179.12 \pm 6.183^{\mathrm{A}}$ & $341.55 \pm 8.729$ \\
\hline & 3 & $156.86 \pm 6.328^{\mathrm{B}}$ & $331.49 \pm 8.900^{b}$ \\
\hline & 4 & $158.33 \pm 6.315^{\mathrm{B}}$ & $325.63 \pm 8.915^{\mathrm{B}, \mathrm{b}}$ \\
\hline & 5 and higher & $131.17 \pm 5.969^{c}$ & $355.92 \pm 8.426^{\mathrm{a}}$ \\
\hline \multirow{2}{*}{ Year of evaluation } & 2017 & $157.74 \pm 5.438^{\mathrm{A}}$ & $327.15 \pm 7.677^{\mathrm{A}}$ \\
\hline & 2018 & $170.89 \pm 5.076^{\mathrm{B}}$ & $360.12 \pm 7.166^{\mathrm{B}}$ \\
\hline \multirow{4}{*}{ Day of treatment } & -3 & $197.24 \pm 9.348^{\mathrm{A}}$ & $382.72 \pm 13.197^{\mathrm{A}, \mathrm{a}}$ \\
\hline & -2 & $174.06 \pm 8.727^{\mathrm{A}}$ & $357.10 \pm 12.320^{\mathrm{A}}$ \\
\hline & -1 & $147.71 \pm 8.482^{\mathrm{B}}$ & $338.94 \pm 11.974^{b}$ \\
\hline & 0 & $138.25 \pm 6.476^{\mathrm{B}}$ & $295.80 \pm 9.141^{\mathrm{B}, \mathrm{c}}$ \\
\hline \multirow{3}{*}{ Type of disease } & Mastitis & $230.71 \pm 3.269^{\mathrm{A}}$ & $447.13 \pm 4.615^{\mathrm{A}}$ \\
\hline & Postpartum diseases & $171.58 \pm 5.602^{\mathrm{B}}$ & $356.15 \pm 7.909^{\mathrm{B}}$ \\
\hline & Metabolic disorder & $90.65 \pm 12.316^{c}$ & $227.64 \pm 17.370^{c}$ \\
\hline
\end{tabular}

Different letters in columns means statistical significance A,B,C $(P<0.01)$; a,b,c $(P<0.05)$.

$11.8 \%$ at the time of eating and $6.7 \%$ at the time of rumination. However, these differences have not been statistically significant yet. There was a much larger decrease in the time of eating and rumination between day 2 and day 1 before the onset of the disease. In this case, a significant $(\mathrm{P}<0.01)$ decrease in eating time of 26.35 min was recorded. However, the decrease in rumination time was slightly lower, only by $18.16 \mathrm{~min}$. Significantly ( $<$ 0.05-0.01) the lowest values of total eating time (138.25 min.) and rumination time $(295.80 \mathrm{~min}$.) were found on the day of recording the disease (0 day). A significant effect on changes in the time of eating and rumination $(\mathrm{P}<0.05-0.01)$ was also demonstrated in the lactation order. The lowest eating time (131.17 min.) was observed in cows on the fifth and subsequent lactation. On the contrary, the highest value (196.11 min.) was recorded for heifers. However, this almost linear decrease with the lactation order at the time of eating was not valid for the time of rumination $(\mathrm{P}<0.05)$. The highest value (363.61 min.) for rumination time was again observed in heifers and in older cows, the value with the order of lactation decreased except of cows at the $5^{\text {th }}$ and higher lactation when the difference of this value compared to heifers was the lowest. The shortest rumination time (325.63 min.) was found in this case in cows on the fourth lactation.

The influence of the type of disease on the change of the evaluated indicators was also evaluated. Significantly $(\mathrm{P}<0.01)$ the highest value of indicators was found in the incidence of mastitis (230.71 and $447.13 \mathrm{~min}$.), followed by postpartum diseases
(171.58 and $356.15 \mathrm{~min}$.$) . The lowest value was$ found in metabolic disorder (227.64 and $90.65 \mathrm{~min}$.).

Finally, the interaction of individual types of disease to changes in eating and chewing time during the 3 days before disease recording and the day of disease detection was evaluated. Tab. III shows a decrease in eating time $3^{\text {rd }}$ days before the recording of mastitis by $14.76 \%(\mathrm{P}<0.01)$. However, no significant differences were found at the time of rumination. There was a significant decrease only $11.45 \%(\mathrm{P}<0.01)$ compared to day 0 and to the $1^{\text {st }}$ day before the disease was recorded. When postpartum diseases occurred, an eating time was reduced from 201.08 (-3 days) to $132.41 \mathrm{~min}$ (0 day). This decrease was statistically significant ( $\mathrm{P}<0.01$ ) and corresponded to about $34.16 \%$. At the time of rumination, a slight decrease was observed between the $3^{\text {rd }}$ and $2^{\text {nd }}$ day before the detection of postpartum diseases. The highest decrease (-58.25 min.) was recorded between the $1^{\text {st }}$ day before the disease and the day of detection this group of disease. Metabolic disorders manifested themselves in the highest decline from all diseases at the time of eating and rumination. The decrease in eating time was by more than 50\%. However, due to the lower incidence of this group of diseases, and thus the large mean errors, these differences were not significantly confirmed. Similarly, in the case of the rumination time, a linear decrease from 298.12 min. to 169.17 min. was observed. However, these differences were not statistically significant for the same reasons. 
III: Evaluation of the interaction of a group of diseases on the time of eating and rumination during the days before the recording of the disease

\begin{tabular}{lccc}
\hline \multirow{2}{*}{ Type of disease } & & Eating time & Rumination time \\
\cline { 2 - 3 } & Day of treatment & $\begin{array}{c}\text { LSM } \pm \text { SELSM } \\
\text { Min/day }\end{array}$ & $\begin{array}{c}\text { LSM } \pm \text { SELSM } \\
\text { Min/day }\end{array}$ \\
\hline \multirow{3}{*}{ Mastitis } & -3 & $245.86 \pm 5.360^{\mathrm{A}}$ & $457.24 \pm 7.566^{\mathrm{A}}$ \\
& -2 & $239.83 \pm 5.350$ & $455.37 \pm 7.553$ \\
& -1 & $227.59 \pm 5.344^{\mathrm{A}}$ & $461.67 \pm 7.545^{\mathrm{A}}$ \\
\hline \multirow{3}{*}{ Postpartum diseases } & 0 & $209.58 \pm 3.720^{\mathrm{B}}$ & $414.23 \pm 5.252^{\mathrm{B}}$ \\
\hline & -3 & $201.08 \pm 10.912^{\mathrm{A}}$ & $392.77 \pm 15.405^{\mathrm{A}}$ \\
& -2 & $188.31 \pm 10.817$ & $365.54 \pm 15.270^{\mathrm{A}}$ \\
& -1 & $164.54 \pm 10.817$ & $362.27 \pm 15.270$ \\
\hline \multirow{2}{*}{ Metabolic disorder } & 0 & $132.41 \pm 5.960^{\mathrm{B}}$ & $304.02 \pm 8.414^{\mathrm{B}}$ \\
\hline & -3 & $144.80 \pm 25.133$ & $298.12 \pm 35.480$ \\
& -2 & $94.03 \pm 23.136$ & $250.41 \pm 32.661$ \\
\hline
\end{tabular}

Different letters in columns in select deseases means statistical significance A,B $(\mathrm{P}<0.01)$. w

\section{DISCUSSION}

Effect of calving on decreasing the time of eating (Braun et al., 2014; Büchel and Sundrum, 2014; Schirmann et al., 2013) and rumination time (Braun et al., 2014; Pahl et al., 2014) are also described by other authors. Average daily eating time 10 days before calving in our research decreased from $200.72 \mathrm{~min} /$ day to $189.37 \mathrm{~min} /$ day in calving day. Time of rumination was decreased from an average $394.13 \mathrm{~min} /$ day 10 days before calving to $271.2 \mathrm{~min} /$ day in calving day. Huzzey et al. (2005) reported an average decrease $25 \mathrm{~min} /$ day of eating time between 10 days before and 2 days after calving. This value is higher than in our results because the data of the compared study did not contain values 2 days before and 2 days after calving. However, results still confirm a decrease of eating time in time before calving. It is necessary to respect the influence of the social behavior of animals. According to Soriani et al. (2012) was average rumination time in period 20 to 6 days before calving $463 \mathrm{~min} /$ day for heifers and $522 \mathrm{~min} /$ day for cows. The lowest time of rumination was in calving day with $262 \mathrm{~min} /$ day for heifers and $278 \mathrm{~min} /$ day for cows. These values from the rumination time monitored by us on the day of calving and perform the confirmatory of the lactation order effect demonstrated in this work. According to Schirmann et al. (2013) cows reduce the eating time by $66 \mathrm{~min} /$ day and the rumination time by $63 \mathrm{~min} /$ day in 3 days before calving and 1 day before calving. Different values of the decrease of the monitored parameters and a negligible difference between the decrease of the eating and rumination time could be caused by different time periods of observation. Through these results, this study confirms reduction in eating and rumination time. Braun et al. (2014) measured the time of eating and rumination in the period 10 days before and 10 days after calving using a pressure sensor. The average pre-calving eating time was $186 \mathrm{~min} /$ day and dropped to $114 \mathrm{~min} /$ day on the day of birth. The rumination time was constant for the duration of the experiment, except calving day. According to Braun et al. (2014), the rumination time ranged from 329 to $391 \mathrm{~min} /$ day and dropped significantly to $214 \mathrm{~min} /$ day on the calving day. Ouellet et al. (2016) found a decrease in mean rumination time on the day of birth by $41 \mathrm{~min} /$ day compared to the previous four days. This result is lower than ours but was obtained in the pre-calving period shorter by 6 days. The rumination time showed the most significant changes in the last six hours before calving. According to this study, rumination time provides the best results in predicting the onset of calving. This conclusion is consistent with our observation that the decrease in rumination time was more pronounced in the pre-calving period than in the eating period.

The influence of individual types of diseases on the time of day eating and ruminatiwon was more significant, which was confirmed by significant differences in the decrease of monitored indicators between mastitis, postpartum diseases (metritis, retained placenta, increase in body temperature), and metabolic problems (ketosis, acidosis, hypocalcemia). According to González et al. (2008) changes in eating time in udder disease are highly variable. A decrease in eating time was observed in eleven of twenty-six dairy cows diagnosed with mastitis, but no consistent change in feeding behavior occurred in the remaining fifteen dairy 
cows. In dairy cows with mastitis, where there was a change in the time of eating, there was a sudden and sharp decrease on the day of diagnosis. In our observation, the eating time was gradually shortened as early as 2 days before the disease was detected. According to Urton et al. (2005) cows showing signs of metritis had on average $22 \mathrm{~min} /$ day shorter feeding times than cows without metritis. With a decrease in the average eating time of $10 \mathrm{~min} /$ day, the probability of a diagnosis of metritis doubled. According to Huzzey et al. (2005) dairy cows with severe metritis had a shorter eating time compared to healthy dairy cows. The decrease in eating time began 2 weeks before the onset of clinical manifestations of metritis. With a decrease in average before occurrence time of $10 \mathrm{~min} /$ day, the probability of severe metritis increased 1.72 times. The results of both of the above studies correspond to our observation, where the eating time decreased by 12.77 minutes two days before the disease was recorded, by another 23.77 minutes the following day, and by an additional 32.13 minutes on the day the disease was recorded. Both of the above studies worked with data from 2 weeks before disease recording, while our research evaluated 3 days before clinical signs and on the day of disease recording. Liboreiro et al. (2015) in the period of 3 weeks before parturition did not observe differences in the daily time of rumination between dairy cows with metritis and healthy dairy cows. This conclusion is not in line with our results, where the rumination time decreased by 88 minutes during the 3 days before and on the day of postpartum disease recording, which corresponds to a decrease of $22.6 \%$. This can be explained to some extent by combining several types of postpartum complications in our evaluation. According to González et al. (2008) ketosis was accompanied by a sharp decrease in the daily eating time of $45 \mathrm{~min} /$ day. The decrease in eating time occurred on average 3.6 days before the diagnosis of the ketosis. This result is consistent with our observation that the time of eating 2 days before the recording of the disease decreased by about $50 \mathrm{~min} /$ day and the next day by another $43 \mathrm{~min} /$ day. According to Goldhawk et al. (2009) increased the probability of subclinical ketosis by 1.9-fold with a decrease in mean eating time of $10 \mathrm{~min} /$ day one week before calving. The sharper decrease in eating time in our work compared to the above study may have been due to a shorter follow-up period. According to Liboreiro et al. (2015) in the period of 3 weeks before calving, the daily time of rumination does not indicate subclinical ketosis and hypocalcemia. In our observation, the rumination time 2 days before the onset of the disease decreased by about 81 minutes. On the other hand, the inconclusiveness of the difference in rumination time in metabolic diseases on different days before the disease can be confirmed by the above-mentioned study.

\section{CONCLUSION}

The influence of the onset of calving and the disease on the time of eating and rumination was conclusive based on the obtained data. Both monitored parameters decreased in the period before calving, while the recorded decrease was more pronounced at the rumination time. Similar trends in a decrease in eating and rumination were also apparent in selected diseases evaluation. Furthermore, there was a difference between the individual diseases, where the highest decrease in both parameters was measured in metabolic disorders and the lowest decreases were recorded in mastitis. Our results show that Vitalimetr 5P can be a good tool to detect changes in the time of eating and rumination in the pre-calving period so in the period at the onset of the disease show a specific decrease can be considered a good tool of detecting the onset of calving and disease.

Acknowledgements

The study was supported from the „S” grant of MŠMT ČR, NAZV project No. QK1910242, CULS project No. SV21-6-21320.

\section{REFERENCES}

AWASTHI, A., AWASTHI, A., RIORDAN, D. and WALSH, J. 2016. Non-invasive sensor technology for the development of a dairy cattle health monitoring system. Computers, 5(4): 23.

BENAISSA, S., TUYTTENS, F. A. M., PLETS, D., TROGH, J., MARTENS, L., VANDAELE, L., JOSEPH, W. and SONCK, B. 2020. Calving and estrus detection in dairy cattle using a combination of indoor localization and accelerometer sensors. Computers and Electronics in Agriculture, 168: 105153.

BRAUN, U., TSCHONER, T. and HÄSSIG, M. 2014. Evaluation of eating and rumination behaviour using a noseband pressure sensor in cows during the peripartum period. BMC Veterinary Research, 10(1): 195. 
BÜCHEL, S. and SUNDRUM, A. 2014. Short communication: Decrease in rumination time as an indicator of the onset of calving. Journal of Dairy Science, 97(5): 3120-3127.

GOLDHAWK, C., CHAPINAL, N., VEIRA, D. M., WEARY, D. M. and von KEYSERLINGK, M. A. G. 2009. Prepartum feeding behavior is an early indicator of subclinical ketosis. Journal of Dairy Science, 92(10): 4971-4977.

GONZÁLEZ, L. A., TOLKAMP, B. J., COFFEY, M. P., FERRET, A. and KYRIAZAKIS, I. 2008. Changes in feeding behavior as possible indicators for the automatic monitoring of health disorders in dairy cows. Journal of Dairy Science, 91(3): 1017-1028.

HELWATKAR, A., RIORDAN, D. and WALSH, J. 2014. Sensor technology for animal health monitoring. International Journal on Smart Sensing and Intelligent Systems, 7(5): 1-6.

HUZZEY, J. M., VEIRA, D. M., WEARY, D. M. and VON KEYSERLINGK, M. A. G. 2007. Prepartum behavior and dry matter intake identify dairy cows at risk for metritis. Journal of Dairy Science, 90(7): 32203233.

HUZZEY, J. M., VON KEYSERLINGK, M. A. G. and WEARY, D. M. 2005. Changes in feeding, drinking, and standing behavior of dairy cows during the transition period. Journal of Dairy Science, 88(7): 2454-2461.

LIBOREIRO, D. N., MACHADO, K. S., SILVA, P. R. B., MATURANA, M. M., NISHIMURA, T. K., BRANDÃO, A. P., ENDRES, M. I. and CHEBEL, R. C. 2015. Characterization of peripartum rumination and activity of cows diagnosed with metabolic and uterine diseases. Journal of Dairy Science, 98(10): 6812-6827.

OUELLET, V., VASSEUR, E., HEUWIESER, W., BURFEIND, O., MALDAGUE, X. and CHARBONNEAU, É. 2016. Evaluation of calving indicators measured by automated monitoring devices to predict the onset of calving in Holstein dairy cows. Journal of Dairy Science, 99(2): 1539-1548.

PAHL, C., HARTUNG, E., GROTHMANN, A., MAHLKOW-NERGE, K. and HAEUSSERMANN, A. 2014. Rumination activity of dairy cows in the 24 hours before and after calving. Journal of Dairy Science, 97(11): 6935-6941.

SAS INSTITUTE INC. 2013. SAS® 9.4 Statements: Reference. Cary, NC: SAS Institute Inc.

SCHIRMANN, K., CHAPINAL, N., WEARY, D. M., VICKERS, L. and VON KEYSERLINGK, M. A. G. 2013. Short communication: Rumination and feeding behavior before and after calving in dairy cows. Journal of Dairy Science, 96(11): 7088-7092.

SORIANI, N., TREVISI, E. and CALAMARI, L. 2012. Relationships between rumination time, metabolic conditions, and health status in dairy cows during the transition period. Journal of Animal Science, 90(12): 4544-4554.

URTON, G., VON KEYSERLINGK, M. A. G. and WEARY, D. M. 2005. Feeding behavior identifies dairy cows at risk for metritis. Journal of Dairy Science, 88(8): 2843-2849.

Contact information

Radim Codl: codl@af.czu.cz (corresponding author)

Jaromír Ducháček: duchacek@af.czu.cz

Jan Pytlík: pytlik@af.czu.cz

Mojmír Vacek: vacekm@af.czu.cz

Marek Vrhel: vrhel@af.czu.cz 
